\title{
An Efficient Method is Required to Transfect Non-dividing Cells with Genetically Encoded Optical Probes for Molecular Imaging
}

\author{
Muhammad AwaIs, ${ }^{* \dagger}$ Svetlana G. VoronInA, $* *$ and Robert SuTton ${ }^{* \dagger}$ \\ *NIHR Liverpool Pancreas Biomedical Research Unit, Institute of Translational Medicine, The University of \\ Liverpool, Royal Liverpool University Hospital, Daulby Street, Liverpool L69 3GA, UK \\ **Department of Cellular and Molecular Physiology, The University of Liverpool, UK
}

\begin{abstract}
Genetically encoded fluorescent and bioluminescent reporters are now widely used for imaging and understanding of intracellular signaling in response to extracellular stimuli in real time in single living cells. Primary cultures are a valuable tool, and are often preferred over transformed or immortalized cell lines, since they are biologically more relevant and important in biomedical research and therapeutic development. To incorporate genetically encoded reporters into the primary culture of non-dividing cells, such as mouse or human pancreatic acinar cells, is not an easy task. This short review discusses the different methods available to transfect cell lines and primary cultures while especially focusing on pancreatic acinar cells with genetically encoded optical reporters to advance knowledge of the pathophysiology of pancreatitis
\end{abstract}

Keywords Genetically encoded optical reporters, acinar cells, pancreatitis, transfection

(Received December 17, 2014; Accepted March 4, 2015; Published April 10, 2015)

\begin{tabular}{llll}
\hline 1 Introduction & 293 & 5 Physical Transfection Methods & 296 \\
2 Transfection Methods & 295 & 6 Acknowledgements & 297 \\
3 Chemical Transfection & 295 & 7 References & 297 \\
4 Biological Transfection & 295 & & \\
\hline
\end{tabular}

\section{Introduction}

A rapid advancement in fluorescence and bioluminescence imaging technology is of great help to cell and chemical biologists for the development of high-throughput assays for the intracellular detection of bioactive small molecules, protein conformational changes, protein localization and dynamics, and the measurement of protein-protein interactions in real-time at the level of single living cells and organisms with high spatial and temporal resolution. ${ }^{1-5}$ Many concepts have emerged to convert biological events into optical signals. These concepts include fluorescence resonance energy transfer, bioluminescence resonance energy transfer, the complementation of split

Muhammad AwaIS received
his Ph.D. in 2005 from the
University of Tokyo. During
his research in Tokyo and at
the Institute for Molecular
Sciences in Okazaki, he
gained extensive knowledge,
skills and experience on
her Ph.D. in 1997 from the
University of Liverpool. Her
thesis was about the regulation
of gastrin processing. She
worked at the Department of
Physiology of the University
of Liverpool as a postdoctoral

$\dagger$ To whom correspondence should be addressed.

E-mail: r.sutton@liverpool.ac.uk (R. S.); awais@liverpool.ac.uk (M. A.) 
Table 1 Transfection methods

\begin{tabular}{|c|c|c|c|}
\hline Class & Advantages & Disadvantages & Ref. \\
\hline \multicolumn{4}{|l|}{ Chemical } \\
\hline $\begin{array}{l}\text { Using cationic lipids, } \\
\text { cationic polymer or } \\
\text { calcium phosphate }\end{array}$ & $\begin{array}{l}\text { No special equipment required, low cost, easy to } \\
\text { use, capable of carrying large DNA insert, low } \\
\text { quantity of DNA/transfection, no safety risk, } \\
\text { effective on most cells lines with low to moderate } \\
\text { cytotoxicity, transient as well as stable transfection } \\
\text { (cationic lipids and calcium phosphate), plenty of } \\
\text { commercially available products }\end{array}$ & $\begin{array}{l}\text { Low efficiency in primary cultures, non-dividing } \\
\text { cells, and cell suspensions, cationic polymers; } \\
\text { transient transfection and toxic to cells in high } \\
\text { concentration, risk of calcium imbalance in the } \\
\text { target cells by calcium phosphate transfection } \\
\text { method }\end{array}$ & $27-33$ \\
\hline \multicolumn{4}{|l|}{ Biological } \\
\hline $\begin{array}{l}\text { Using viruses, such } \\
\text { as, adenovirus, } \\
\text { adeno-associated } \\
\text { virus or lentivirus }\end{array}$ & $\begin{array}{l}\text { High transfection efficiency (adenovirus, transient } \\
\text { transfection; adeno-associated and lentivirus; } \\
\text { transient as well as stable transfection), good } \\
\text { expression, can accommodate reasonable insert } \\
\text { size (adenovirus, } \sim 7.5 \mathrm{~kb} \text {; adeno-associated virus, } \\
5 \mathrm{~kb} \text {; lentivirus, } \sim 9 \mathrm{~kb} \text { ), able to transfect dividing } \\
\text { and non-dividing cells; genome integration into the } \\
\text { hos cells (adenovirus, no; adeno-associated and } \\
\text { lentivirus, yes) }\end{array}$ & $\begin{array}{l}\text { Safety issues (biosafety level } 2 \text { laboratory needed), } \\
\text { labor intensive, high cost, can take weeks to } \\
\text { achieve an appropriate titer of the viral particles, } \\
\text { packaging cell line required, limitation of DNA } \\
\text { insert size, toxic when high virus titers are used }\end{array}$ & $\begin{array}{c}35-37 \\
62,63\end{array}$ \\
\hline \multicolumn{4}{|l|}{ Physical } \\
\hline Microinjection & $\begin{array}{l}\text { Selective and targeted transfection, good technique } \\
\text { to transfer DNA into embryonic stem cells, high } \\
\text { efficiency, works for both dividing and non- } \\
\text { dividing cells }\end{array}$ & $\begin{array}{l}\text { Technically demanding and costly, labor intensive, } \\
\text { needs special equipment }\end{array}$ & $42-44$ \\
\hline Biolistic & $\begin{array}{l}\text { Fast with good transfection efficiency, uses small } \\
\text { amount of DNA, DNA-coated nano-particles can } \\
\text { be transfected deep into a tissue or organ }\end{array}$ & $\begin{array}{l}\text { Preparation of micro or nanoparticles, needs special } \\
\text { equipment, optimization is required to reduce } \\
\text { cellular toxicity }\end{array}$ & 45,46 \\
\hline Laser-mediated & $\begin{array}{l}\text { Efficient, selective and targeted transfection, works } \\
\text { for both dividing and non-dividing cells }\end{array}$ & $\begin{array}{l}\text { Expensive laser based equipment needed, require the } \\
\text { cells to be firmly attached. }\end{array}$ & $47-49$ \\
\hline Magnet-mediated & $\begin{array}{l}\text { Easy to perform, fast gene accumulation within the } \\
\text { target cells, able to transfect dividing and non- } \\
\text { dividing cells and primary cell cultures, less DNA } \\
\text { consumption }\end{array}$ & Suspension cells need to be immobilized. & $50-53$ \\
\hline Electroporation & $\begin{array}{l}\text { Popular and easy to perform, good transfection } \\
\text { efficiency, works well for dividing and non- } \\
\text { dividing cells suspension cells. }\end{array}$ & $\begin{array}{l}\text { Special equipment needed, cellular toxicity is } \\
\text { generally high, almost } 3 \text { times DNA quantity/ } \\
\text { transfection is required compared to a chemical } \\
\text { transfection. }\end{array}$ & $54-59$ \\
\hline
\end{tabular}

fragments from fluorescent or bioluminescent proteins, circular permutation and protein cyclization. ${ }^{6-13}$ The imaging and quantitative measurement of cellular events in the physiological environment of live cells and animals is pivotal for translational research and drug discovery for different diseases. ${ }^{14}$ Cell death via apoptotic, necrotic and recently necroptosis ${ }^{15}$ pathways is a hot topic of research in basic and translational science. For imaging apoptosis, both fluorescent and bioluminescent genetically encoded probes have been developed. ${ }^{8,13}$ In contrast, specific probes for the investigation of the signaling mechanisms that initiate necrosis have yet to be developed, but are highly desirable. A lack of knowledge about the specific substrate(s) in necrosis, e.g. those that recognizes calpain activation during necrosis, is an obstacle to developing probes for imaging necrosis,${ }^{16}$ requiring further fundamental research of the process. Moreover, molecular probes for the imaging of necroptosis in real-time would be of great help to understand the cross-talk between apoptosis and necrosis in the pathogenesis of different diseases.

A number of cell lines have been established to study cellular events in real-time. Genetically encoded probes can be transfected, transiently or produced stable cell line, in these transformed immortalized cell lines to image the cellular signaling process under a microscope. Cell lines, however, may not reflect the actual condition in vivo, and results may not be reproducible in living animals. Therefore, primary cultures are often preferred over cell lines, since they are biologically more relevant in translational research. To incorporate a molecular probe into a primary culture of non-dividing cells, such as mouse or human pancreatic acinar cells, is not an easy task. Acinar cells are the primary site of injury in acute pancreatitis (AP). ${ }^{17} \mathrm{AP}$ is an inflammatory disorder of the pancreas. There is currently no specific therapy for AP, despite significant morbidity and mortality of this disease worldwide. ${ }^{18}$ The pathophysiology of AP begins with injury and dysfunction of acinar cells, which are exocrine cells of the pancreas. The acinar cells are designed to synthesize and secrete digestive enzymes and precursors of digestive enzymes, which are stored in secretory granules. The secretion mechanism is exocytosis controlled by cytosolic $\mathrm{Ca}^{2+}$ signals. These signals are generated by binding of the hormone cholecystokinin (CCK) and/or neurotransmitter acetylcholine to their respective receptors on the acinar cell membrane. Hyperstimulation with supraphysiological CCK concentrations induce a cytosolic $\mathrm{Ca}^{2+}$ overload, intracellular digestive enzyme activation, vacuolization and necrosis. ${ }^{19,20}$ To control the disease, protection of the 
pancreas from necrosis is extremely important. Much of the signaling for necrotic cell-death pathway activation originates from mitochondria. In response to $\mathrm{Ca}^{2+}$ overload and/or reactive oxygen species, the mitochondrial permeability transition pore (MPTP) opens across the inner mitochondrial membrane. ${ }^{21}$ This allows an unregulated entry and exit of particles up to $1.5 \mathrm{kDa}$, as well as water, into and out of the mitochondrial matrix. This results in the loss of inner mitochondrial-membrane potential, associated with mitochondrial swelling and rupture of the outer mitochondrial membrane. Opening of the MPTP plays a key role to trigger necrosis in several tissues and organs, perhaps playing such a role in the pancreas. ${ }^{22,23}$

Until now, unfortunately, there is very little use of such probes in research concerning pancreatitis using a primary culture of acinar cells. Especially, specific probes to understand signaling mechanism that initiate cell death via necrosis and necroptosis are desperately required. These molecular probes would also be of great help to advance an understanding of ischemiareperfusion injury of the heart, brain and kidney, muscular dystrophies, neuro-degeneration and cancer. ${ }^{22,24-26}$ We have recently set up collaboration with Ozawa's laboratory $3,5,11,13$ at the University of Tokyo to develop probes to advance our knowledge of pathophysiology of AP. The bottleneck in using genetically encoded reporters is to transfect such reporters into the highly polarized and productive pancreatic acinar cells. No continuous cell line of mouse or human, terminally differentiated acinar cells, exists. Primary cultures of acinar cells cannot be kept alive for many days because the cells quickly lose their acinar characteristics, typically dying within $48-72 \mathrm{~h}$. To make use of this narrow window of opportunity, an efficient method is required to transfect molecular probe(s) into acinar cells for imaging cellular events in real time.

\section{Transfection Methods}

Broadly, there are three ways to introduce an exogenous DNA into live cells: chemical, biological and physical transfection, as shown in Table 1 .

\section{Chemical Transfection}

Chemical transfection methods were the first to be used to introduce foreign genes into mammalian cells. In chemical transfection, gene transfer is achieved by cationic lipids, cationic polymers or calcium phosphate. ${ }^{27-29}$ Cationic lipids, cationic polymers or calcium phosphate act as carrier molecules to overcome the cell membrane barrier. The principle consists of a spontaneous interaction of negatively charged DNA with a positively charged carrier molecule, polymer or lipid, thus enabling the carrier/DNA positively-charged complex to interact with the cell membrane to be incorporated into the cell, most probably, by endocytosis. ${ }^{30}$ Various endocytic pathways operate in eukaryotic cells, i.e. clathrin-dependent and -independent pathways, the latter including phagocytosis, macropinocytosis and caveolae-mediated internalization. The relative contribution of each pathway in carrier/DNA internalization has been poorly defined to date, although the involvement of the clathrinmediated pathway for the cellular entry of the complex into the cells has been firmly established. ${ }^{31}$ Chemical transfection is economical, easy to perform, and there is little safety risk involved; it is also effective on most cell lines, has relatively low cytotoxicity and there is no need of any special equipment. Cationic polymers are suitable for transient transfection, while

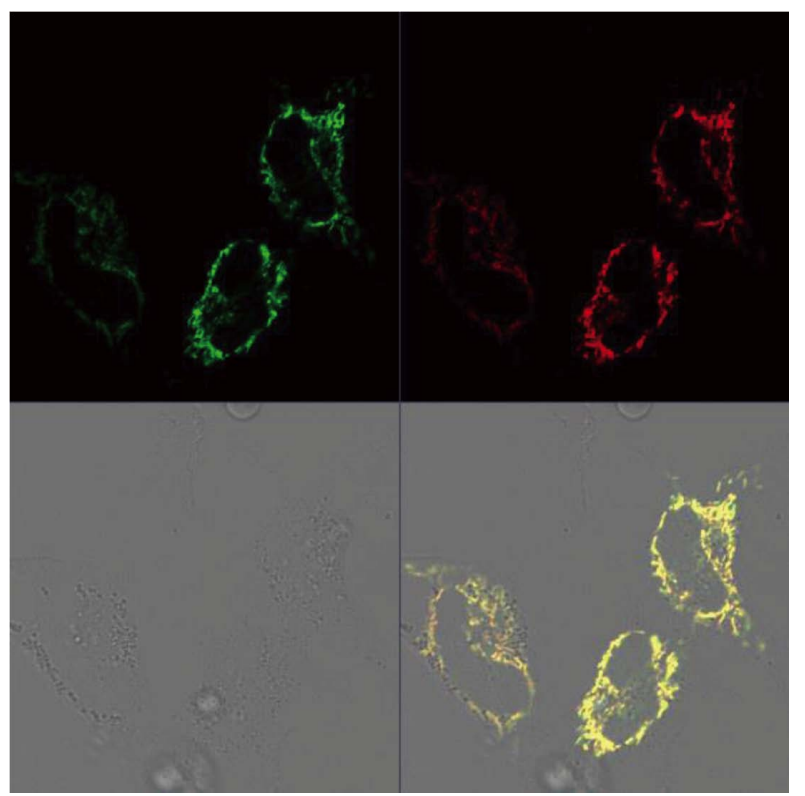

Fig. 1 HeLa cells transfected with the CypD-YFP reporter (yellow fluorescent protein, YFP, is attached on the C-terminus of cyclophilin D, CypD) using LipofectAMINE 2000 (Invitrogen). CypD is a mitochondrial matrix protein and is an essential driver of the MPTP opening to stimulate cell death. ${ }^{22}$ Mitochondrial localization of the CypD-YFP reporter was confirmed by loading the cells with the cell permeable mitochondrial positively-charged dye tetramethyl rhodamine methyl ester (TMRM). CypD-YFP (green, $\lambda_{\mathrm{em}}: 530 \mathrm{~nm}$ ) overlaps perfectly on TMRM (red, $\lambda_{\text {em }}$ : 575 ), showing mitochondrial localization.

cationic lipids and calcium phosphate are suitable for both the transient and stable transfection of a variety of cell lines. The image in Fig. 1 represents the transfection of HeLa cells by chemical transfection. This method is capable of carrying a large DNA insert including bacterial artificial chromosome based vectors, ${ }^{32,33}$ which permit the use of tens of kilobases long sequences; however the efficiency is moderate and varies from cell-type-to cell type. Despite all of this, chemical transfection is not an efficient way in the case of primary neurons and primary cultures of various cells and is an unsuccessful method to transfect primary cultures of acinar cells. In the case of the calcium phosphate transfection technique, there is always a risk of a calcium imbalance in the cell, which may interfere with physiological calcium signaling. ${ }^{19,34}$

\section{Biological Transfection}

Viral-based transfection methods are the most successful ways to achieve gene expression in hard-to-transfect cell lines and primary cultures. ${ }^{35-38}$ This method involves the use of viral vectors, which are powerful tools for gene delivery ex vivo and in vivo making use of nature's most efficient and highly evolved mechanisms for infecting cells. The adenovirus belongs to the Adenoviridae family; being a nonenveloped virus with broad tropism, adenoviral vectors are useful for gene transfer because of a number of key features: 1) adenoviral vectors rapidly infect a broad range of cell types and can achieve high levels of gene transfer compared to other available vectors; 2) adenoviral vectors can accommodate relatively large segments of DNA (up to $7.5 \mathrm{~kb}$ ) and transduce these transgenes in both dividing cells 


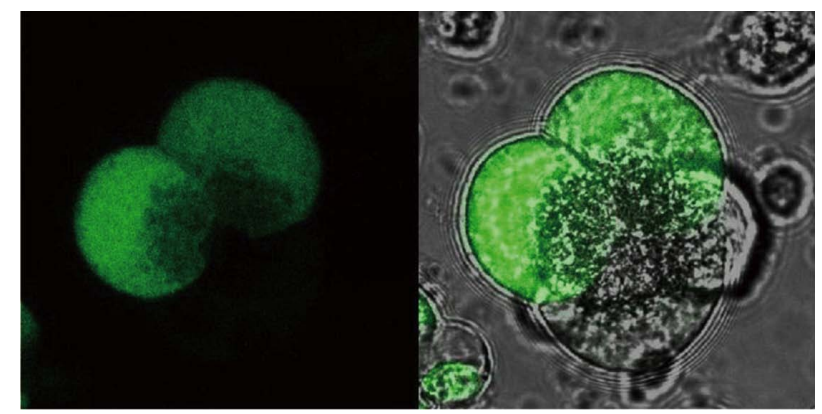

Fig. 2 Acinar cells isolated from a mouse pancreas are transfected with YFP-STIM1 (stromal interaction molecule) probe using replication deficient adenovirus (Vector Biolab). Acinar cells seeded in a $3 \mathrm{~cm}$ glass bottom poly-d-lysine coated dish and were infected with virus concentration $5.4 \times 10^{6} \mathrm{pfu} / \mathrm{mL}$ and incubated overnight $(12-14 \mathrm{~h})$ at $35^{\circ} \mathrm{C}$. STIM1 translocates to endoplasmic reticulumplasma membrane (PM) junctions and activates Orai channels in the PM. ${ }^{38}$ The image was kindly provided by our collaborator Professor Alexei Tepikin.

and non-dividing cells; and 3) adenoviral vectors are relatively easy to manipulate using recombinant DNA techniques. This large double-stranded DNA virus does not integrate into the host genome, making it limited to transient, episomal expression of transgenes. However, this also means that adenoviruses do not interfere with the host genome. Other vectors of interest include adeno-associated virus, herpes simplex virus, retroviruses and lentiviruses, a subset of the retrovirus family. Lentiviruses (e.g., HIV-1) are of particular interest because they are well studied, can infect quiescent cells, and can integrate into the host cell genome to allow stable, long-term transgene expression. ${ }^{36}$ The following steps are involved in viral transfection: 1) generation of recombinant virus containing the transgene via gene cloning; 2) amplification of viral particles in a packaging cell line and virus isolation; 3) purification and determination of the titer of viral particles (in some cases it could take weeks to achieve an appropriate titer); 4) infection of cell type of interest. Though expensive, labor intensive, limited by the insert size, and accompanied by some safety issues, viral transfection has been the most successful method to transfect, and is applicable to almost all cell types and primary cultures including acinar cells (Fig. 2). ${ }^{35-38}$ Viral transfection becomes even more expensive and complicated when more than one genetically encoded reporter is required, e.g. to co-transfect cells for imaging protein-protein interaction using intermolecular fluorescence resonance energy-transfer ${ }^{39,40}$ or protein fragment complementation assays. ${ }^{11,41}$

\section{Physical Transfection Methods}

For the physical transfection of nucleic acids, a variety of physical tools have been developed, but consideration has been made of the delicate but extremely organized structure of the cell membrane, which has to be crossed with the minimum disturbance to avoid cell injury, and to achieve efficient transfection. Microinjection, biolistic particle delivery, laser based, magnet mediated and electroporation technology are in routine use for physical transfection.

Microinjection involves directly injecting DNA or RNA into intact eukaryotic cells, and provides an efficient means for studying transcription and translations of specific genes. ${ }^{42-44}$
This technique is useful for selective and targeted transfection, especially in neurons. ${ }^{43,44}$ Microinjection is very labor-intensive and demands much skill. Moreover, this technique is difficult to apply for cell suspensions, such as Jurkat and U937 cells, and primary cultures including acinar cells, which are loosely attached to the surface. Biolistic transfection is another method that can be applied to transfect cells, tissue slices, or living organs. The method involves shooting the recipient with DNAcoated gold particles, and constructs can be transferred to a depth of $100 \mu \mathrm{m}$ into a tissue or organ..$^{45}$ An improvement of this technology has been demonstrated by O'Brien et al. using nanoparticles instead of microparticles. ${ }^{46}$ Though expensive and potentially causing damage to cells, it would be interesting to see the efficiency of this method, to date there is no reported example of the transfection of acinar cells using this technology. The laser mediated poration of cellular membrane has recently emerged as an exciting technique of gene delivery into mammalian cells. A laser is focused through the objective of an inverse microscope onto the cell surface to create a spatially confined pore, which allows the diffusion of extracellular molecules into the cytoplasm. ${ }^{47}$ A tightly focused femtosecond (fs) pulsed near infrared (NIR) laser beam has proven to provide single-cell selectivity, localized operation and low toxicity with a consistent performance. ${ }^{48}$ The laser method is efficient for most cells tightly attached with the surface and the transfection can be seen in real time. A recent improvement of laser transfection is named GNOME, gold nanoparticle mediated laser transfection. ${ }^{49}$ The cells are incubated with gold nanoparticles (AuNP) with a diameter of $200 \mathrm{~nm}$. The AuNP attach to the cell membrane. The sample is then irradiated by a weakly focused laser beam. The particle-laser interaction leads to plasmon resonances on the particles. These induce thermal and near field effects, which in turn can evoke transient cell membrane permeabilization, enabling diffusion of extracellular molecules into the cytoplasm. For laser-based transfection, an expensive laser-microscope system is required. Magneticmediated transfection uses a magnetic force exerted upon gene vectors associated with magnetic nanoparticles to drive the vector towards the target cells. ${ }^{50}$ This technique exploits the natural pathways (endocytotic mechanism) of cells during the transfection process, without disrupting the cell membrane, resulting in high cell viability post-transfection. Magneticmediated transfection has several advantages: 1) low DNA concentration/reaction is required; 2) fast gene accumulation within the target cells; 3 ) easy to handle and considerably reduced incubation time; 4) can be applied to variety of cell lines, primary cultures, neurons and hard-to-transfect cells. ${ }^{51,53}$ We are in the process of optimizing this method to transfect a primary culture of pancreatic acinar cells.

Electroporation is an easy and quick method, and can accomplish exogenous DNA incorporation into the cells. This technique involves the exposure of cell membranes to highintensity electric pulses which causes a temporary destabilization in certain areas of the cell. This allows charged extracellular material, e.g., plasmids, to enter the cell by electrophoresis. ${ }^{54-58}$ This method is successful to transfect cell suspensions, primary cultures and hard to transfect cells. ${ }^{57,58}$ There are some drawbacks associated with this method. For example, a large amount of DNA is required, cell survival is low, and physiologists wish to avoid stressing freshly isolated primary cultures which have already gone through a crude process of isolation from a live tissue. Kim et al. demonstrated the development and use of a novel electroporation device using a pipette tip chamber instead of a cuvette for a more uniform electric field and better cell viability. ${ }^{59}$ Different laboratories including our group have 
(a)

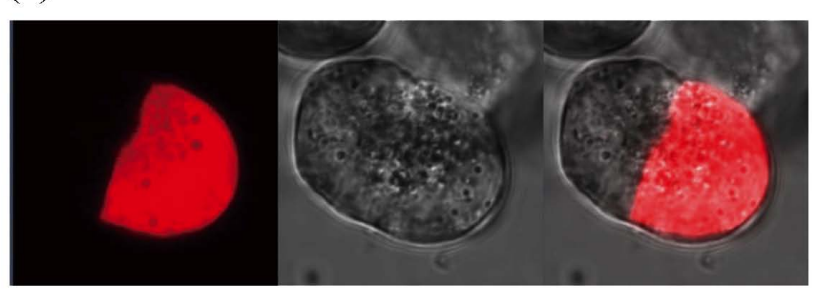

(b)

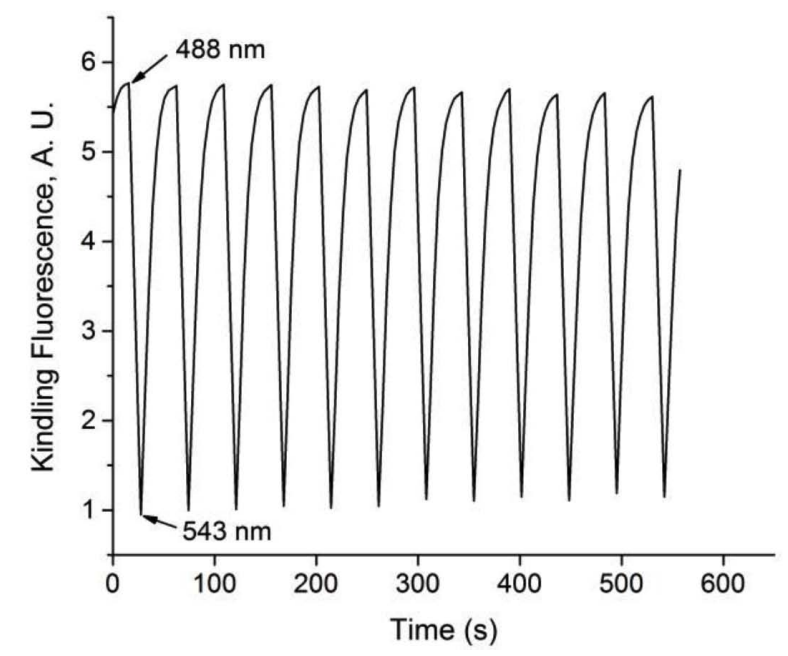

Fig. 3 (a) Acinar cells isolated from a mouse pancreas are transfected with photoactivatable kindling fluorescent protein (KFP) ${ }^{60}$ using an electroporation system, Neon ${ }^{\circledR}$ Transfection, by Life Technologies-Invitrogen. To electroporate a primary culture of acinar cells, the following protocol was used: voltage, 800 volts; pulse width, $20 \mathrm{~ms}$; pulse number, 2 . HeNe laser $543 \mathrm{~nm}$ and argon $488 \mathrm{~nm}$ lasers were used to activate (switch on, $\lambda_{\mathrm{em}}: 600 \mathrm{~nm}$ ) and quench (switch off), respectively, the KFP. (b) The switching on and off of the KFP is a reversible process.

endeavored to optimize a protocol of electroporation for primary cultures of acinar cells to obtain reasonable transfection efficiency with minimum stress (Fig. 3, unpublished data). To our knowledge, this is for the first time an image of perfectly healthy primary culture of acinar cells transfected with a genetically encoded optical reporter has been achieved by electroporation. According to our experience a gap of $60-$ $90 \mathrm{~min}$ between the isolation and electroporation processes gives time for cells to recover and assists in achieving higher transfection rates.

In summary, therefore, an easy, efficient and economical method is required for the transfection of primary cultures of non-dividing cells, so as to better understand the localization, translocation and movements of a gene of interest, visualize protein conformational changes, and assess drug-protein, and protein-protein interactions (e.g. of druggable targets) for translational research and drug discovery. The transfection efficiency varies partly because the strength of the membrane barrier differs from cell type to cell type. To overcome this problem, combinations of chemical and physical methods of transfection, such as magnetofection, ${ }^{61}$ could produce better results with a reasonable cost for the delivery of even large DNA into easy as well as hard-to-transfect cells.

\section{Acknowledgements}

This work was supported by the UK NIHR Biomedical Research Unit Funding Scheme.

\section{References}

1. K. Nienhaus and G. U. Nienhaus, Chem. Soc. Rev., 2014, 43, 1088 .

2. B. Richier and I. Salecker, Wiley Interdiscip. Rev.: Dev. Biol., 2015, 4, 161.

3. M. Hattori, S. Haga, H. Takakura, M. Ozaki, and T. Ozawa, Proc. Natl. Acad. Sci. U. S. A., 2013, 110, 9332.

4. R. Kojima, H. Takakura, T. Ozawa, Y. Tada, T. Nagano, and Y. Urano, Angew. Chem., Int. Ed., 2013, 52,1175.

5. M. Awais and T. Ozawa, Mol. Biosyst., 2011, 7, 1376.

6. M. Awais, M. Sato, X. Lee, and Y. Umezawa, Angew. Chem., Int. Ed., 2006, 45, 2707.

7. A. Miyawaki, J. Llopis, R. Heim, J. M. McCaffery, J. A. Adams, M. Ikura, and R. Y. Tsien, Nature, 1997, 388, 882.

8. H. J. Kang, J. H. Kim, and S. J. Chung, Biosens. Bioelectron., 2015, 15, 413.

9. H. Hoshino, Y. Nakajima, and Y. Ohmiya, Nat. Methods, 2007, 4, 637.

10. A. De, P. Ray, A. M. Loening, and S. S. Gambhir, FASEB J., 2009, 23, 2702.

11. L. Yang, Y. Nasu, M. Hattori, H. Yoshimura, A. Kanno, and T. Ozawa, Anal. Chem., 2013, 85, 11352.

12. S. S. Wigdal, J. L. Anderson, G. J. Vidugiris, J. Shultz, K. V. Wood, and F. Fan, Curr. Chem. Genomics, 2008, 2, 16.

13. A. Kanno, Y. Yamanaka, H. Hirano, Y. Umezawa, and T. Ozawa, Angew. Chem., Int. Ed., 2007, 46, 7595.

14. O. Kepp, L. Galluzzi, M. Lipinski, J. Yuan, and G. Kroemer, Nat. Rev. Drug Discovery, 2011, 10, 221.

15. S. He, L. Wang, L. Miao, T. Wang, F. Du, L. Zhao, and X. Wang, Cell, 2009, 137, 1100.

16. D. E. Goll, V. F. Thompson, H. Li, W. Wei, and J. Cong, Physiol. Rev., 2003, 83, 731.

17. F. S. Gorelick and E. Thrower, Clin. Gastroenterol. Hepatol., 2009, 7, S10.

18. E. P. Dellinger, C. E. Forsmark, P. Layer, P. Lévy, E. Maraví-Poma, M. S. Petrov, T. Shimosegawa, A. K. Siriwardena, G. Uomo, D. C. Whitcomb, and J. A. Windsor, Ann. Surg., 2012, 00, 1.

19. R. Mukherjee, D. N. Criddle, A. Gukvoskaya, S. Pandol, O. H. Petersen, and R. Sutton, Cell Calcium, 2008, 44, 14.

20. J. Murphy, D. N. Criddle, M. Sherwood, M. Chvanov, R. Mukherjee, E. McLaughlin, D. Booth, J. V. Gerasimenko, M. G. T. Raraty, P. Ghaneh, J. P. Neoptolemos, O. V. Gerasimenko, A. V. Tepikin, G. M. Greem, J. R. Reeve, O. H. Petersen, and R. Sutton, Gastroenterology, 2008, 135, 632.

21. A. P. Halestrap, J. Mol. Cell. Cardiol., 2009, 46, 821.

22. T. Nakagawa, S. Shimizu, T. Watanabe, O. Yamaguchi, K. Otsu, H. Yamagata, H. Inohara, T. Kubo, and Y. Tsujimoto, Nature, 2005, 434, 652.

23. N. Shalbueva, O. A. Mareninova, A. Gerloff, J. Yuan, R. T. Waldron, S. J. Pandol, and A. S. Gukovskaya, Gastroenterology, 2013, 44, 437.

24. C. P. Baines, R. A. Kaiser, N. H. Purcell, N. S. Blair, H. Osinska, M. A. Hambleton, E. W. Brunskill, M. R. Sayen, R. A. Gottlieb, G. W. Dorn, J. Robbins, and J. D. Molkentin, Nature, 2005, 434, 658. 
25. X. Wang, Y. Carlsson, E. Basso, C. Zhu, C. I. Rousset, A. Rasola, B. R. Johansson, K. Blomgren, C. Mallard, P. Bernardi, M. A. Forte, and H. Hagberg, J. Neurosci., 2009, 29, 2588.

26. N. K. Devalaraja, A. M. Diener, and B. J. Padanilam, Am. J. Physiol. Renal Physiol., 2009, 297, F749.

27. C. K. Jiang, D. Connolly, and M. Blumenberg, J. Invest. Dermatol., 1991, 97, 969.

28. D. Hoekstra, J. Rejman, L. Wasungu, F. Shi, and I. Zuhorn, Biochem. Soc. Trans., 2007, 35, 68.

29. M. Jordan and F. Wurm, Methods, 2004, 33, 136.

30. S. Chesnoy and L. Huang, Annu. Rev. Biophys. Biomol. Struct., 2000, 29, 27.

31. I. S. Zuhorn, R. Kalicharan, and D. Hoekstra, J. Biol. Chem., 2002, 277, 18021.

32. W. J. Montigny, S. F. Phelps, S. Illenye, and N. H. Heintz, Biotechniques, 2003, 35, 796.

33. M. Rostovskaya, J. Fu, M. Obst, I. Baer, S. Weidlich, H. Wang, A. J. H. Smith, K. Anastassiadis, and A. F. Stewart, Nucleic. Acids Res., 2012, $1,1$.

34. P. S. Castano, A, A. Schmid, I. Anderie, M. F. Bermejo, G. M. Salido, and A. González, J. Sci. Technol., 2104, 2, 1.

35. P. J. Padfield, A. C. Elliott, and J. J. Baldassare, Pfluegers Arch., 1998, 436, 782.

36. A. G. Teschemachera, J. F. R. Patonb, and S. Kasparov, Adv. Drug Delivery Rev., 2005, 57, 79.

37. S. Djurovic, N. Iversen, S. Jeansson, F. Hoover, and G. Christensen, Mol. Biotechnol., 2004, 28, 21.

38. G. Lur, L. P. Haynes, I. A. Prior, O. V. Gerasimenko, S. Feske, O. H. Petersen, R. D. Burgoyne, and A. V. Tepikin, Curr. Biol., 2009, 19, 1648.

39. D. M. Grant, W. Zhang, E. J. McGhee, T. D. Bunney, C. B. Talbot, S. Kumar, I. Munro, C. Dunsby, M. A. A. Neil, M. Katan, and P. M. W. French, Biophys. J., 2008, 95, L69.

40. Y. Niino, K. Hotta, and K. Oka, PLoS One, 2009, 4, e6036.

41. T. Ozawa, Y. Natori, M. Sato, and Y. Umezawa, Nat. Methods, 2007, 45, 413.

42. C. P. Liu, D. L. Slate, R. Gravel, and F. H. Ruddle, Proc. Natl. Acad. Sci. U. S. A., 1979, 76, 4503.

43. B. Alsina, T. Vu, and S. Cohen-Cory, Nat. Neurosci., 2001, 4, 1093.

44. K. Kohara, A. Kitamura, M. Morishima, and T. Tsumoto,
Science, 2001, 291, 2419.

45. R. C. Murphy and A. Messer, Mol. Ther., 2001, 3, 113.

46. J. A. O'Brien and S. C. R. Lummis, BMC Biotecnol., 2011, $11,66$.

47. Y. Shirahata, N. Ohkohchi, H. Itagak, and S. Satomi, J. Invest. Med., 2001, 49, 184.

48. U. K. Tirlapur and K. Konig, Nature, 2002, 418, 290.

49. D. Heinemann, M. Schomaker, S. Kalies, M. Schieck, and R. Carlson, PLoS One, 2013, 8, e58604.

50. C. Plank, U. Schillinger, F. Scherer, C. Bergemann, J. S. Rémy, F. Krötz, M. Anton, J. Lausier, and J. Rosenecker, Biol. Chem., 2003, 384, 737.

51. C. H. Lee, E. Y. Kim, K. Jeon, J. C. Tae, K. S. Lee, Y. O. Kim, M. Y. Jeong, C. W. Yun, D. K. Jeong, S. K. Cho, J. H. Kim, H. Y. Lee, K. Z. Riu, S. G. Cho, and S. P. Park, Stem Cells Dev., 2008, 17, 133.

52. S. I. Jenkins, M. R. Pickard, N. Granger, and D. M. Chari, ACS Nano, 2011, 5, 6527.

53. T. Buerli, C. Pellegrino, K. Baer, B. Lardi-Studler, I. Chudotvorova J. M. Fritschy, I. Medina, and C. Fuhrer, Nat. Protocols, 2007, 2, 3090.

54. T. K. Wong and E. Neumann, Biochem. Biophys. Res. Commun., 1982, 107, 584.

55. G. H. Swift, Y. Liu, S. D. Rose, L. J. Bischof, S. Steelman, A. M. Buchberg, C. V. E. Wright, and R. J. MacDonald, Mol. Cell Biol., 1998, 18, 5109.

56. T. Inoue and R. Krumlauf, Nat. Neurosci., 2001, 4, 1156.

57. A. Chebel, J. P. Rouault, and I. Urbanowicz, J. Biol. Chem., 2009, 284, 35725.

58. D. J. Killock, M. Parsons, and M. Zarrouk, J. Biol. Chem., 2009, 284, 8833.

59. J. A. Kim, K. Cho, M. S. Shin, W. G. Lee, N. Jung, C. Chung, and J. K. Chang, Biosens. Bioelectron., 2008, 23, 1353.

60. D. M. Chudakov, V. V. Belousov, A. G. Zaraisky, V. V. Novoselov, D. B. Staroverov, D. B. Zorov, S. Lukyanov, and K. A. Lukyanov, Nat. Biotecnol., 2003, 21, 191.

61. C. Plank, O. Zelphati, and O. Mykhaylyk, Adv. Drug Delivery Rev., 2011, 63, 1300.

62. S. A. Vorburger and K. K. Hunt, Oncologist, 2002, 7, 46.

63. D. S. Anson, Genet. Vaccines Ther, 2004, 2, 1. 